\title{
Application of Pd-Sn Modified Ru-Ir Electrode For Treating High Chlorine Ammonia-Nitrogen Wastewater
}

\section{Zhen-xing Yang ( $\nabla$ yangzx_cup@163.com )}

China University of Petroleum Beijing https://orcid.org/0000-0002-6446-4643

\section{Wen-yu Xie}

Guangdong University of Petrochemical Technology

Fang-fang Ye

Guangdong University of Petrochemical Technology

De-hao Li

Yangjiang Vocational and Technical College

\section{Research Article}

Keywords: Pd-Sn, modified Ru-Ir electrode, Electro-catalytic technology, High chlorine ammonia-nitrogen wastewater, Nitrogen removal, Indirect oxidation

Posted Date: September 16th, 2021

DOl: https://doi.org/10.21203/rs.3.rs-867616/v1

License: (9) This work is licensed under a Creative Commons Attribution 4.0 International License. Read Full License 


\section{Abstract}

Electro-catalytic technology has attracted increasing attention as a promising approach for wastewater treatment, owing to its easy operation, minimal generation of secondary pollution, small foot-print and rapid start-up. In this work, the chlorine evolution potential of the Pd-Sn modified ruthenium(Ru)iridium(Ir) electrode was investigated for electro-catalytic treatment of high chlorine ammonia-nitrogen wastewater. The effect of reaction conditions on the removal of ammonia-nitrogen, kinetics and apparent activation energy of the electro-catalytic treatment of ammonia-nitrogen were studied. The possible denitrification process of high chlorine ammonia-nitrogen wastewater treated by electrocatalysis was discussed. The results indicated that the chlorine evolution potential of the Pd-Sn modified Ru-Ir electrode was $1.0956 \mathrm{~V}$ (vs. SCE). The rule of electro-catalytic treatment of high chlorine ammonia-nitrogen conformed to zero-order kinetics, and the removal process was endothermic reaction with the apparent activation energy of $14.089 \mathrm{~kJ} / \mathrm{mol}$. With the current is $0.5 \mathrm{~A}$, the removal efficiency of ammonia-nitrogen could achieve $100 \%$ at the reaction time of $40 \mathrm{~min}$. Indirect oxidation played an essential role in the electro-catalytic ammonia-nitrogen removal using the Pd-Sn modified Ru-Ir electrode. This paper demonstrated that the electro-catalytic technology was a promising approach for efficiently treating the high chlorine ammonia-nitrogen wastewater.

\section{Introduction}

Ammonia-nitrogen wastewater generated from complex refinery and chemical enterprises is detrimental to environment, as they can cause not only an offensive smell, but also eutrophication that is fatal to aquatic life. With poor biodegradability, the wastewater in such industry is often characterized as high ammonia-nitrogen concentration of $50-200 \mathrm{mg} / \mathrm{L}$ and high salt content (calculated by chloride ion) of $1 \mathrm{~g} / \mathrm{L}-25.59 \mathrm{~g} / \mathrm{L}(Y$ in-fang 2010). Therefore, it is difficult for traditional sewage treatment plants to treat this wastewater, which increases the huge pressure of environmental control and economic cost of the refinery and causes potential danger to the environment.

The commonly used technologies for treating high chlorine ammonia-nitrogen wastewater mainly include biological degradation (Mulder et al. 2006; Kim et al. 2008; Zhang et al. 2008; Ruiz et al. 2003; Fang et al. 1993; Schmidt and Bock 1997; Li et al. 2018; Strous et al. 1997; Jing and Lin 2004; Zhang et al. 2013), physical-chemical method(Kurama et al. 2002; Ozturk et al. 2003; MIN et al. 2009), physical adsorption (Huo et al. 2012; Zhou and Boyd 2014), advanced oxidation (Lin et al. 2009; Lin et al. 2009; Wang et al. 2008; Shavisi et al. 2014; Zhou et al. 2016), and chemical precipitation (El Diwani et al. 2007; Huang et al. 2017; Huang et al. 2014; Shaban et al. 2017). These technologies have great constraints for treating wastewater containing high level of ammonia-nitrogen. Biological methods for treating ammonianitrogen wastewater rely largely on microorganisms, which have stringent requirements for environmental conditions, such as wastewater toxicity, $\mathrm{C} / \mathrm{N}$ ratio, salt concentration, and operational parameters(Zhang et al. 2018). Besides, wastewaters containing high chlorine ammonia-nitrogen are easy to dehydrate microorganisms, making them lose the cell activity and integrity. Advanced oxidation technologies, such as ultrasonic and photocatalysis, usually require high costs, high energy consumption and complex 
operational skills. With respect to adsorption technology, although the operating conditions are relatively simple, there are a variety of competitive ions that can form adsorption with ammonia-nitrogen in the high chlorine ammonia-nitrogen wastewater, resulting in poor removal efficiency of ammonia-nitrogen, and the desorption of the adsorbent itself is also a difficulty. The chemical precipitation uses magnesium compounds and chemical substances containing phosphate to react with ammonia-nitrogen to generate magnesium ammonium phosphate and remove the ammonia-nitrogen. This method will use a large number of magnesium compounds and phosphorus-containing substances, but the reaction is not complete, which will make a large amount of phosphorus into the environment, causing re-pollution of water bodies.

Electro-catalytic technology that can achieve organic degradation through electron transfer has attracted increasing attention as a promising approach for wastewater treatment, a owing to its easy operation, minimal generation of secondary pollution, remote control, a wide range of operating temperature, rapid start-up, small foot-print, and high removal efficiency of contaminants (Ding et al. 2018; Ye et al. 2016). In particular, electrochemical processes exhibit a superiority in eliminating nitrogenous contaminants to biological processes since $\mathrm{NH}_{4}{ }^{+}-\mathrm{N}$ is readily oxidized at the anode while nitrates and nitrites can be reduced at the cathode( $\mathrm{Li}$ et al. 2010). At the same time, hydrogen is produced on the cathode, which can be collected as an energy source. Although electrochemical technology has disadvantage of high power consumption, compared with physical, chemical, and biological technologies, it exhibits superiority in the treatment of ammonia-nitrogen wastewater with high toxicity, poor biodegradability, and high salt content.

As one of the major mechanisms for electrochemical ammonia removal from wastewater, direct anodic oxidation proceeds via sequential dehydrogenation of adsorbed ammonia on electrode surfaces when a sufficiently positive potential was applied to the electrode. Therefore, electrode materials are the key factors in the treatment of ammonia-nitrogen wastewater by electro-catalytic technology. The majority of research on the direct oxidation of ammonia has been carried out using platinum (Pt) (Duong et al. 2018). The modification of Pt catalysts with other electrode materials, such as $\mathrm{Ti} / \mathrm{SnO}_{2}+\mathrm{Sb} / \mathrm{PbO}_{2}$, has been well documented for efficient removal of ammonia-nitrogen in coking wastewater(Ma et al. 2012). Electrochemical technology using $\mathrm{Ti} / \mathrm{RuO}_{2}-\mathrm{IrO}_{2}$ as an anode can synergically remove total ammonianitrogen (TAN) and nitrite in circulating aquaculture wastewater(Ruan et al. 2016). $\mathrm{SnO}_{2}$ electrode was found to be efficient for removal of organic matter, however, its lifespan was short; Similarly, toxic $\mathrm{Pb}$ can be dissolved from $\mathrm{PbO}_{2}$ electrode, resulting in secondary pollution of wastewater.

$\mathrm{RuO}_{2}-\mathrm{IrO}_{2}$-based catalyst is considered as an excellent electrode material in terms of ammonia oxidation, owing to its stability, high electrical conductivity, and excellent chlorine-evolution performance(He et al. 2013). However, the $\mathrm{RuO}_{2}-\mathrm{IrO}_{2}$ electrode has relatively poor corrosion resistance, and its service life is still short in industrial practical application. By contrast, $\mathrm{Pd}$ is not only more cost-effective, but also has better corrosion resistance, compared to $\mathrm{Pt} . \mathrm{Pd}-\mathrm{SnO}_{2} / \mathrm{C}$ has been reported to exhibit good electrical conductivity and electro-catalytic performance(Hameed 2017).With this regard, the modification of Ru-Ir electrode with 
Pd-Sn has been explored by combining the catalytic performance of $\mathrm{Sn}$ and corrosion resistance of Pd, to significant enhance the electro-catalytic performance of the Pd-Sn-based catalyst derived from Ru-Ir electrode. However, to date, the effect of modification of Ru-Ir electrode with Pd-Sn on electro-catalytic treatment of high chlorine ammonium-nitrogen wastewater has not been studied.

Furthermore, in the process of electro-catalytic oxidation of the high chlorine ammonia-nitrogen wastewater, reaction conditions can affect the performance of electro-catalytic ammonia-nitrogen, which can provide theoretical guidance for electro-catalytic treatment of high chlorine ammonia-nitrogen wastewater. In general, the main factors affecting the industrial application of electro-catalytic treatment of high chlorine ammonia-nitrogen wastewater include chloride ion concentration, initial concentration of ammonia-nitrogen, current, voltage, electrode material, $\mathrm{pH}$, temperature, types and content of organic matter, suspended matter etc(Chen et al. 2007; Candido et al. 2013; Liu et al. 2009). For instance, Ma et al. prepared the Ti/SnO${ }_{2}+\mathrm{Sb} / \mathrm{PbO}_{2}$ anode to investigate the effects of operating parameters including current density, anode material, $\mathrm{pH}$ and the concentration of chloride by orthogonal array experimental design and reported that the anode material, current density, and chloride concentration have significant influences on the ammonia removal(Ma et al. 2012). Kim et al. evaluated the effects of the $\mathrm{pH}$ and the chloride ion in the solution, kinds of anodes on the electrolytic decomposition of ammonia and revealed that the performances of the electrode were totally in the order of $\mathrm{RuO}_{2} \approx \mathrm{IrO}_{2} \square \mathrm{Pt}$ in both the acid and alkali conditions and the ammonia decomposition was the highest at a current density of 80 $\mathrm{mA} / \mathrm{cm}^{2}$ (Kim et al. 2006). Furthermore, the $\mathrm{Ti} / \mathrm{RuO}_{2} / \mathrm{IrO}_{2}$, the Pt/ITO electrode, and the BDD anode were also applied to the treatment of ammonia-nitrogen wastewater(Wang et al. 2016; Liu et al. 2012; Alcocer et al. 2018). However, the effect of chloride ion concentration, $\mathrm{pH}$, and temperature on the electro-catalytic treatment of high chlorine ammonia-nitrogen wastewater by the Pd-Sn modified Ru-Ir electrode remains largely unknown.

Within this context, this study is aimed to evaluate the electro-catalytic effect of the modification of Ru-Ir electrode with $\mathrm{Pd}-\mathrm{Sn}$ on treating high chlorine ammonia-nitrogen wastewater. More specifically, this study is aimed to : (1) investigate the chlorine evolution performance using the modification of Ru-Ir electrode with Pd-Sn; (2) evaluate the influence of operational conditions on the removal of ammonia-nitrogen, kinetics and apparent activation energy; (3) explore the possible denitrification process in the electrocatalytic treatment for high chlorine ammonia-nitrogen wastewater.

\section{Experiment}

\subsection{Chemicals and materials}

Sodium chloride, palladium chloride, stannum chloride pentahydrate and Ruthenium(III) chloride hydrate were purchased from ALADDIN Reagent (Shanghai) Co., Ltd. Anhydrous ethanol, Iridium( ( $)$ chloride hydrate, sodium hydroxide and oxalic acid were bought from Shanghai Macklin Biochemical Co., Ltd.

The titanium(Ti) matrix and Ru-Ir electrode were obtained from Baoji Zhong Tai Material Co. Ltd. 


\subsection{Preparation of modified Ru-Ir electrodes with Pd-Sn}

Ruthenium trichloride, iridium tetrachloride, palladium chloride, and tin tetrachloride were mixed an appropriate amount of polyethylene glycol in a beaker containing $10 \mathrm{~mL}$ deionized water with the mole Ru-Ir ratio of 2:1, the mole Pd-Sn ratio of 3:1. Besides, the mass of Pd-Sn accounted for $1.5 \%$ of the total mass of the elements. After oscillating in an oscillator for $2 \mathrm{~h}$, the solution was sonicated in an ultrasonic instrument for $1.5 \mathrm{~h}\left(40^{\circ} \mathrm{C}, 45 \mathrm{kHz}\right)$. Thereafter, it was oscillated in the oscillator for another $30 \mathrm{~min}$ to make the active material completely dissolve.

In order to modify Pd-Sn with Ru-Ir electrode, the Ti plate $(5.4 \mathrm{~cm} \times 5.0 \mathrm{~cm} \times 0.2 \mathrm{~cm})$ was polished using coarse and fine sandpaper. After a metallic luster was observed, the Ti plate was put into $10 \%$ sodium hydroxide solution and heated at $100^{\circ} \mathrm{C}$ for $2 \mathrm{~h}$, followed by $10 \%$ oxalic acid for 2 h's mild boiling treatment. Then $0.1 \mathrm{~mL}$ precursor solution of the modified Ru-lr electrode with Pd-Sn was added to the etched Ti plate each time. The solution on the surface of the electrode was kept flat. After natural drying, the solution was dried in the oven at $105^{\circ} \mathrm{C}$ for $5 \mathrm{~min}$ and then placed in the muff furnace for thermal oxidation at $500^{\circ} \mathrm{C}$ for $15 \mathrm{~min}$. The impregnation, drying, and thermal oxidation were repeated for 15 times. Thereafter, it was kept at a constant temperature of $500^{\circ} \mathrm{C}$ in a muffle furnace for $4 \mathrm{~h}$, and then naturally annealed to room temperature. In this way, a the modification of modified Ru-Ir electrode using titanium-based Pd-Sn was well prepared, with catalyst content of $15 \mathrm{mg} / \mathrm{cm}^{2}$ (based on the total mass of elements).

\subsection{Experimental setup}

The experiment was carried out in a $210 \mathrm{~mL}$ special electrolytic cell with introduction of $200 \mathrm{~mL}$ high chlorine ammonia-nitrogen wastewater. The electrode dimension was $5.4 \mathrm{~cm} \times 5.0 \mathrm{~cm} \times 0.2 \mathrm{~cm}$. The Pd-Sn modified Ru-Ir electrode was used as the anode, while the platinum electrode was used as the cathode. The anode and cathode electrodes were spaced $4 \mathrm{~cm}$ apart and placed parallel in the electrolytic cell. The wastewater was stirred with a magnetic stirrer (700 rpm), and a DC Power Supply (DH1718E-5 DC Power Supply) was used to provide the required current and voltage. Hydrochloric acid and sodium hydroxide were used to adjust the initial $\mathrm{pH}$, while sodium chloride was used to adjust the concentration of chloride ions. Thermostatic water bath was used to maintain the temperature of the reaction solution at $25^{\circ} \mathrm{C}$.

\subsection{Analytical methods for electrochemical performance}

In saturated sodium chloride, the linear sweep voltammetry (LSV) of the Pd-Sn-modified Ru-Ir electrode was measured by an electrochemical workstation (CHI660E Shanghai Chenhua Instrument Co., Ltd.), and the change in the chlorine evolution potential of the electrode was observed. The cyclic voltammetry (CV) and electrochemical impedance spectroscopy (EIS) of the Pd-Sn modified Ru-Ir electrode were measured in the simulated high chlorine ammonia-nitrogen wastewater.

\subsection{Analytical methods for water quality}


The $\mathrm{pH}$ of wastewater was measured with a $\mathrm{pH}$ meter. The temperature was measured using a thermometer. The concentrations of $\mathrm{NH}_{3}-\mathrm{N}, \mathrm{NO}_{3}-\mathrm{N}$ and $\mathrm{NO}_{2}-\mathrm{N}$ were determined by a gas phase molecular absorption spectrometer (GMA3378), while the TN level was measured usinga liquid phase total organic carbon analyzer (TOC-VCPH).

High Performance Liquid Chromatography (HPLC) coupled with a LC-10AT vacuum degassing pump, a DGU-12A quaternary pump, a SIL-10AD autosampler, and a fluorescence detector (Japan Shimadzu RF$10 \mathrm{AXL}$ ), was used to measure the contents of 2, 3-dihydroxybenzoic acid and 2, 5-dihydroxybenzoic acid, in order to determine the concentration of hydroxyl radical. HPLC included The separation was achieved using a XDB-C18 chromatographic column $(5 \mu \mathrm{m} \times 4.6 \mathrm{~mm} \times 150 \mathrm{~mm})$. The mobile phase was set up using $3 \%$ acetic acid solution-Methanol $(75: 25 ; \mathrm{v} / \mathrm{v})$ at the flow rate of $1.0 \mathrm{~mL} / \mathrm{min}$, and the injection volume was $10 \mu \mathrm{L}$ at temperature of $30^{\circ} \mathrm{C}$.

\section{Results And Discussions}

\subsection{The chlorine-evolution performance}

Figure 1 presents a comparison of the chlorine evolution potential between the unmodified Ru-Ir electrode and the modified Ru-Ir electrode with Pd-Sn using saturated calomel electrode (SCE) as a reference electrode in the saturated sodium chloride solution. As shown in Fig. 1, the chlorine evolution potential of the unmodified ruthenium-iridium electrode and the Pd-Sn-modified Ru-Ir electrode were $1.1663 \mathrm{~V}$ and $1.0956 \mathrm{~V}$, respectively. The chlorine evolution potential of the Pd-Sn-modified Ru-Ir electrode was lower compared to the unmodified electrode, indicating that the Pd-Sn-modified Ru-Ir electrode exhibited a better chlorine evolution performance. At 1.3V, the current of the unmodified Ru-Ir electrode and the Pd-Snmodified Ru-Ir electrode were $0.0040 \mathrm{~A}$ and $0.2373 \mathrm{~A}$, respectively, indicating that the conductivity of the Pd-Sn-modified Ru-Ir electrode in saturated sodium chloride was better than that of the unmodified Ru-Ir electrode. Previous studies indicated that the following chemical reactions may occur in the electrocatalytic treatment of wastewater containing chlorine and ammonia-nitrogen(A et al. 2014; Chen et al. 2020):

$\mathrm{Cl}^{-} \rightarrow \cdot \mathrm{Cl}+\mathrm{e}^{-}(1)$

$2 \mathrm{Cl}^{-} \rightarrow \mathrm{Cl}_{2}($ aq. $)+2 \mathrm{e}^{-}(2)$

$\mathrm{MO}_{\mathrm{x}}+\mathrm{H}_{2} \mathrm{O} \rightarrow \mathrm{MO}_{\mathrm{x}}(\cdot \mathrm{OH})+\mathrm{H}^{+}+\mathrm{e}^{-}$

$\mathrm{MO}_{\mathrm{x}}(\cdot \mathrm{OH})+\mathrm{Cl}^{-} \rightarrow \mathrm{MO}_{\mathrm{x}}(\cdot \mathrm{OCl})+\mathrm{H}^{+}+2 \mathrm{e}^{-}(4)$

$\mathrm{MO}_{\mathrm{x}}(\cdot \mathrm{OCl})+\mathrm{Cl}^{-} \rightarrow \mathrm{MO}_{\mathrm{x}+1}+\mathrm{Cl}_{2}$ (aq. $)+\mathrm{e}^{-}$

$\mathrm{Cl}_{2}$ (aq.) $+\mathrm{H}_{2} \mathrm{O} \rightarrow \mathrm{H}^{+}+\mathrm{Cl}^{-}+\mathrm{HClO}(6)$ 
$\mathrm{HClO} \rightleftharpoons \mathrm{H}^{+}+\mathrm{ClO}^{-}(7)$

Firstly, the electrode exchanges electrons with water to generate hydroxyl radicals $\left(\mathrm{MO}_{x}(\cdot \mathrm{OH})\right)$ as adsorbent, which reacts with chloride ions to produce hypochlorite active group $\left(\mathrm{MO}_{\mathrm{x}}(\cdot \mathrm{OCl})\right)$ and chlorine gas, or chloride ions directly exchange electrons with the electrode to produce chlorine gas. This process is shown in Equations (1) (5). Thereafter, the generated chlorine gas reacts with water to produce hypochlorous acid. $\mathrm{MO}_{\mathrm{x}}(\cdot \mathrm{OH}), \mathrm{MO}_{\mathrm{x}}(\cdot \mathrm{OCl})$, chlorine gas, and hypochlorous acid are used to indirectly oxidize ammonia-nitrogen, as shown in Equations (6) (7).In the present study, the Pd-Sn modified Ru-Ir electrode in saturated sodium chloride solution exhibited good performance of both chlorine-evolution and electrical conductivity, which was conducive to the progress of the chlorine-evolution reaction and promoted the generation of the residual chlorine. Therefore, it can be concluded that the modified Ru-Ir electrode with Pd-Sn was suitable for the application of electro-catalytic oxidation of ammonia-nitrogen with chloride ions as the medium.

\subsection{Effect of reaction conditions on electro-catalytic oxidation of ammonia-nitrogen}

\subsubsection{Effect of chloride ion concentration}

Figure 2 illustrates the influence of chloride ion concentration on ammonia-nitrogen removal at the initial ammonia-nitrogen concentration of $50 \mathrm{mg} / \mathrm{L}$. As shown in Fig. 2, with the same reaction time, high ammonia-nitrogen removal rate could be achieved with high concentration of chloride ion, compared to low chloride concentration, indicating that $t$. high level of chloride ion was conducive to promoting the electro-catalytic removal of ammonia-nitrogen. For instance, at reaction time of 30 min,the removal rates of ammonia-nitrogen were $8.70 \%, 12.13 \%, 39.73 \%, 66.84 \%$ and $97.91 \%$, respectively, when the chloride ion concentrations were $1000 \mathrm{mg} / \mathrm{L}, 3000 \mathrm{mg} / \mathrm{L}, 5000 \mathrm{mg} / \mathrm{L}, 7000 \mathrm{mg} / \mathrm{L}$ and $10000 \mathrm{mg} / \mathrm{L}$, respectively. However, the increase in the concentration of chloride ion exerted different influences on the removal rate of ammonia-nitrogen. When the concentration of chloride ions increased from 1000 to $3000 \mathrm{mg} / \mathrm{L}$, the removal rate of ammonia-nitrogen increased by $1.72 \%$ for each $1000 \mathrm{mg} / \mathrm{L}$ increase of chloride ion concentration. When the concentration of chloride ion was in the range of $3000 \sim 5000 \mathrm{mg} / \mathrm{L}$, the removal rate of ammonia-nitrogen increased by $13.8 \%$ for every $1000 \mathrm{mg} / \mathrm{L}$ increase in chloride ion concentration. When the concentration of chloride ion ranged from 5000 to $7000 \mathrm{mg} / \mathrm{L}$, the removal rate of ammonianitrogen increased by $13.56 \%$ for each $1000 \mathrm{mg} / \mathrm{L}$ increase of chloride ion concentration. However, when the concentration of chloride ion was in the range of $7000 \sim 10000 \mathrm{mg} / \mathrm{L}$, the removal rate of ammonianitrogen increased by $10.35 \%$ for every $1000 \mathrm{mg} / \mathrm{L}$ increase of chloride ion concentration. This finding indicated that with the increase of chloride ion concentration, the effective removal rate of ammonianitrogen by chloride ion increased firstly and then decreased. It was evidenced that the optimal chloride ion concentration should be maintained at $5000 \sim 7000 \mathrm{mg} / \mathrm{L}$, in order to maintain the high efficiency of removal rate of ammonia-nitrogen. 
To achieve the same ammonia-nitrogen removal rate of $25.78 \%$, the time required for ammonia-nitrogen removal were $90.00,60.00,18.52,11.19$ and $7.75 \mathrm{~min}$, when the chloride ion concentrations were 1000, $3000,5000,7000$ and $10000 \mathrm{mg} / \mathrm{L}$, respectively. The higher the concentration of chloride ions, the shorter the electro-catalytic time needed for ammonia-nitrogen removal. When the concentration of chloride ions was less than $5000 \mathrm{mg} / \mathrm{L}$, the required time was approximately $60 \mathrm{~min}$, while when the concentration of chloride ions was greater than $5000 \mathrm{mg} / \mathrm{L}$, the required time was about $20 \mathrm{~min}$. This finding implied that the optimal concentration of chloride ion should be kept at least $5000 \mathrm{mg} / \mathrm{L}$ to maintain the efficient removal of ammonia-nitrogen. In summary, in the process of electro-catalytic oxidation treatment of the high chlorine ammonia-nitrogen wastewater, the chloride ion concentration should be kept around 5000$7000 \mathrm{mg} / \mathrm{L}$. Excessive chloride ion concentration would reduce the efficiency of ammonia-nitrogen removal, increase the cost of reagents, and affect the subsequent treatment of wastewater. Therefore, in the actual process of electro-catalytic treatment for the high chlorine ammonia-nitrogen, it is necessary to comprehensively consider the concentration of chloride ions concentration on the premise of ensuring the effective removal of ammonia-nitrogen. In the present study, the chloride ion concentration of $5000 \mathrm{mg} / \mathrm{L}$ was selected for subsequent experiments.

\subsubsection{Effect of $\mathrm{pH}$}

Figure 3 shows the influence of $\mathrm{pH}$ on the removal rate of ammonia-nitrogen when the initial concentration of ammonia-nitrogen was $50 \mathrm{mg} / \mathrm{L}$, with the concentration of chloride ions of $5000 \mathrm{mg} / \mathrm{L}$. When the reaction time was short, $\mathrm{pH}$ exhibited little effect on the removal of ammonia-nitrogen. When the electro-catalytic reaction time exceeded $40 \mathrm{~min}$, the removal efficiency of ammonia-nitrogen increased with the increase of initial $\mathrm{pH}$. When the reaction time was $50 \mathrm{~min}$, the removal rates of ammonianitrogen were $46.46 \%, 54.52 \%, 55.97 \%, 69.45 \%$ and $72.27 \%$ at the $\mathrm{pH}$ was $3,5,7,9$ and 11 , respectively. This finding revealed that with the increase of $\mathrm{pH}$, the removal rate of ammonia-nitrogen gradually increased, suggesting that alkaline conditions were more conducive to the electro-catalytic oxidation of ammonia-nitrogen. The reason behind this phenomenon might because there was a large amount of hydroxide $\left(\mathrm{OH}^{-}\right)$in the solution under alkaline conditions, and chlorine gas was more likely to transform into oxidizing substances, such as sodium hypochlorite, which promoted the removal of ammonianitrogen. In addition, under acidic conditions, since a large amount of $\mathrm{H}^{+}$existed in the solution, the ionic radius of hydronium (2.82 $\mathrm{A}$ ) was smaller than that of $\mathrm{NH}_{4}{ }^{+}(3.31 \mathrm{~A})$, and $\mathrm{NH}_{4}{ }^{+}$migrated slowly in a fixed electric field(Fang et al. 2018), resulting in poor removal of ammonia-nitrogen. Meanwhile, chlorine gas produced by the anode electrode had low solubility in acidic solution and was directly volatilized from the wastewater. Thus, few oxidizing substances, such as hypochlorous acid produced in the solution, were observed, resulting in the poor removal of ammonia-nitrogen. By comparison, it is found that when the initial $\mathrm{pH}$ was 9 and 11, the difference in the removal rate of ammonia-nitrogen was small $(2.82 \%)$, suggesting that the increase in the initial $\mathrm{pH}$ of the ammonia-nitrogen wastewater had a small promoting effect on the ammonia-nitrogen removal. If the initial $\mathrm{pH}$ was too high, a large amount of alkali needs to be added, which would increase the reagent cost. Therefore, in the process of electro-catalytic treatment of ammonia-nitrogen wastewater, the effective removal of ammonia-nitrogen can be promoted by controlling the initial $\mathrm{pH}$ of ammonia-nitrogen wastewater. 


\subsubsection{Effect of temperature}

Figure 4 shows the influence of reaction temperature on the removal of ammonia-nitrogen at the initial concentrations of ammonia-nitrogen and the concentration of chloride ion of $50 \mathrm{mg} / \mathrm{L}$, and $5000 \mathrm{mg} / \mathrm{L}$, respectively. Reaction temperature directly affects the energy of the reactions and the migration rate of pollutants between the bulk solution and the electrode surface(Xu et al. 2017), leading to the variety in removal efficiency of pollutants. As can be seen from Fig. 4, the temperature could significantly affect the removal effect of ammonia-nitrogen. When the temperature was $30,40,50,67$, and $78^{\circ} \mathrm{C}$, the slope of the fitting line of the ammonia-nitrogen removal curve was $0.93,1.00,1.32,1.58$, and 1.92, respectively, indicating a positive correlation between the temperature and the ammonia-nitrogen removal rate. When the temperature was between $30^{\circ} \mathrm{C}$ and $40^{\circ} \mathrm{C}$, the difference of the slope of the ammonia-nitrogen removal curve was only 0.07 , indicating that temperature played a minor role in ammonia-nitrogen removal when the temperature was less than $40^{\circ} \mathrm{C}$. When the temperature was greater than $40^{\circ} \mathrm{C}$, the larger the slope of the ammonia-nitrogen removal curve was observed with the increase in temperature, suggesting that the ammonia-nitrogen removal rate increased rapidly. At reaction time of $50 \mathrm{~min}$, the removal efficiencies of ammonia-nitrogen were $46.74 \%, 48.50 \%, 66.67 \%, 76.90 \%$, and $93.01 \%$, at temperature of $30,40,50,67$, and $78^{\circ} \mathrm{C}$, respectively. To ensure that the removal efficiency of ammonianitrogen ( $\geq 66.67 \%$ ) was high, the electro-catalytic treatment temperature should be greater than $50^{\circ} \mathrm{C}$. The influence of temperature on ammonia-nitrogen removal was mainly through increasing the energy of the system to improve the reaction rate of the system and then reducing the resistance of ammonianitrogen removal. In addition, with the increase of temperature, the Brownian motion of the molecules in the system was intensified, which improved the contact opportunity between the ammonia-nitrogen molecules, and promoted the electro-catalytic removal of ammonia-nitrogen. In summary, the electrocatalytic oxidation of ammonia-nitrogen removal rate can be improved by regulating the reaction temperature $\left(\geq 40^{\circ} \mathrm{C}\right)$, however, the high temperature would increase energy consumption. Therefore, it is necessary to take an overall consideration on the energy consumption, the service life of the equipment, and the removal efficiency of ammonia-nitrogen, in order to rationally adjust and control the reaction temperature of electro-catalytic treatment of ammonia-nitrogen.

\subsection{Kinetic studies}

Figure $5 \mathrm{a}, 5 \mathrm{c}$, and $5 \mathrm{e}$ presents the influence of chloride ion concentration, $\mathrm{pH}$, and temperature on the removal effect of ammonia-nitrogen. It can be seen that the electro-catalytic removal process of ammonia-nitrogen belonged to the zero-order reaction, since there was a linear relationship between the residual ratio of ammonia-nitrogen and the reaction time under different reaction conditions. The reaction rates, half-lives $\left(t_{1 / 2}\right)$, and linear correlation coefficients under different conditions are shown in Table 1. The relationship between different reaction conditions and reaction rates is shown in Fig. 5b, 6d, and $6 f$. 
Table 1

Kinetic parameters under different reaction conditions

\begin{tabular}{|c|c|c|c|c|}
\hline \multicolumn{2}{|c|}{ Reaction condition } & \multirow{2}{*}{$\begin{array}{l}\text { Correlation coefficient } \\
0.980\end{array}$} & \multirow{2}{*}{$\begin{array}{l}\mathbf{k}\left(\mathrm{min}^{-1}\right) \\
0.0028\end{array}$} & \multirow{2}{*}{$\begin{array}{l}\text { Half lives (min) } \\
178.57\end{array}$} \\
\hline Chloride & 1000 & & & \\
\hline concentration & 3000 & 0.995 & 0.0047 & 106.38 \\
\hline \multirow[t]{3}{*}{$(\mathrm{mg} / \mathrm{L})$} & 5000 & 0.982 & 0.0114 & 43.86 \\
\hline & 7000 & 0.999 & 0.0219 & 22.83 \\
\hline & 10000 & 0.999 & 0.0326 & 15.34 \\
\hline \multirow[t]{5}{*}{$\mathrm{pH}$ value } & 3 & 0.985 & 0.009 & 55.56 \\
\hline & 5 & 0.971 & 0.012 & 41.67 \\
\hline & 7 & 0.989 & 0.012 & 41.67 \\
\hline & 9 & 0.973 & 0.014 & 35.71 \\
\hline & 11 & 0.941 & 0.015 & 33.33 \\
\hline \multirow{5}{*}{$\begin{array}{l}\text { Temperature } \\
\left({ }^{\circ} \mathrm{C}\right)\end{array}$} & 30 & 0.996 & 0.009 & 55.56 \\
\hline & 40 & 0.995 & 0.010 & 50.00 \\
\hline & 50 & 0.977 & 0.013 & 38.46 \\
\hline & 67 & 0.960 & 0.016 & 31.25 \\
\hline & 78 & 0.991 & 0.019 & 26.32 \\
\hline
\end{tabular}

Combined with the analysis in Table 1 and Fig. 5b, it can be found that the higher the concentration of chloride ions, the faster the removal reaction rate of ammonia-nitrogen, indicating that the concentration of chloride ions could promote the reaction rate of ammonia-nitrogen removal. A positive linear correlation between the reaction rate of ammonia-nitrogen removal and chloride ion concentration was observed as bellows:

$y=3.5148 \times 10^{-6} x-0.0036\left(R^{2}=0.9650\right)(8)$

Where, $y$ denotes the reaction rate of ammonia-nitrogen removal $\left(\mathrm{min}^{-1}\right)$, and $\mathrm{x}$ denotes the concentration of chloride ion $(\mathrm{mg} / \mathrm{L})$. However, taking the reagent cost and wastewater post-treatment into consideration, high chloride ion concentrations would increase the cost of the wastewater treatment and cause pressure on subsequent treatment facilities. Therefore, in the process of electro-catalytic treatment of high chlorine ammonia-nitrogen wastewater, the concentration of chloride ion should be controlled at $5000 \sim 7000 \mathrm{mg} / \mathrm{L}$ to achieve both cost-effectiveness and high removal efficiency of ammonia-nitrogen.

According to Table 1 and Fig. 5d, the reaction rate of the electro-catalytic processes increased with the increase of $\mathrm{pH}$. It was evidenced that the reaction rate of the electro-catalytic processes was positively 
correlated with $\mathrm{pH}$, as bellows:

$y=7.0000 \times 10^{-4} x+0.0075\left(R^{2}=0.9615\right)(9)$

Where, $y$ represents the reaction rate of the electro-catalytic processes $\left(\mathrm{min}^{-1}\right)$, and $\mathrm{x}$ represents $\mathrm{pH}$. To achieve the effective and rapid electro-catalytic removal of ammonia-nitrogen, the $\mathrm{pH}$ in the wastewater should be greater than 7 .

In combination with Table 1 and Fig. 5f, the reaction rate in the electro-catalytic processes increased with the increase of temperature. The reaction rate in the electro-catalytic processes exhibited a positive linear correlation with temperature, as bellows:

$y=2.0792 \times 10^{-4} x+0.0025\left(R^{2}=0.9873\right)(10)$

Where, $y$ denotes the reaction rate of ammonia-nitrogen removal $\left(\mathrm{min}^{-1}\right)$, and $\mathrm{x}$ denotes the temperature $\left({ }^{\circ} \mathrm{C}\right)$. Therefore, high temperature should be selected to achieve the effective and rapid removal of ammonia-nitrogen in the electro-catalytic process. However, given the fact that high temperature would cause high energy consumption and accelerate the corrosion damage of equipment, the reaction temperature should be maintained at $50^{\circ} \mathrm{C}$.

\subsection{The apparent activation energy}

The reaction rates of the electro-catalytic process at $30^{\circ} \mathrm{C}, 40^{\circ} \mathrm{C}, 50^{\circ} \mathrm{C}, 67^{\circ} \mathrm{C}$ and $78^{\circ} \mathrm{C}$ are shown in Table 2. The apparent activation energy in the electro-catalytic process was calculated using Arrhenius equation, as below :

$\ln \mathrm{k}=-\mathrm{E}_{\mathrm{a}} / \mathrm{RT}+\ln \mathrm{A}(11)$

Table 2

Calculation parameters of the apparent activation energy

\begin{tabular}{|llll|}
\hline $\mathrm{T}(\mathrm{K})$ & $\mathbf{k}\left(\mathrm{min}^{-1}\right)$ & $\ln \mathbf{k}$ & $\mathbf{1 / T}\left(\mathrm{K}^{-1}\right)$ \\
\hline 303.15 & 0.009 & -4.71053 & 0.003299 \\
\hline 313.15 & 0.010 & -4.60517 & 0.003193 \\
\hline 323.15 & 0.013 & -4.34281 & 0.003095 \\
\hline 340.15 & 0.016 & -4.13517 & 0.002940 \\
\hline 351.15 & 0.019 & -3.96332 & 0.002848 \\
\hline
\end{tabular}

Where, $E_{a}$ denotes activation energy, $\mathrm{kJ} / \mathrm{mol} ; \mathrm{R}$ denotes the gas molar constant, $8.314 \mathrm{~J} /(\mathrm{mol} \cdot \mathrm{K}) ; \mathrm{K}$ denotes the removal rate of ammonia-nitrogen, $\min ^{-1}$; A denotes the pre-exponential factor, $\min ^{-1} ; \mathrm{T}$ denotes the thermodynamic temperature, $\mathrm{K}$. 
According to the data in Table 2, the Ink 1/T diagram can be got in Fig. 6 . And the formula 12 is obtained by fitting curve with origin software:

$\ln (k)=-1694.58 \times(1 / T)+0.8595\left(R^{2}=0.9865\right)$

The high correlation coefficient $\left(\mathrm{R}^{2}>0.98\right)$ of the fitting curve indicated a high accuracy. According to formula (12), when $-E_{a} / R$ was -1694.58 , $E_{a}$ was equal to $14.089 \mathrm{~kJ} / \mathrm{mol}$, and the apparent activation energy was $14.089 \mathrm{~kJ} / \mathrm{mol}$ accordingly. This finding suggested that the removal of ammonia-nitrogen through electro-catalytic oxidation was generally an endothermic process, thus, high temperature can enhance the removal rate of ammonia-nitrogen.

\subsection{The possible denitrification pathway for ammonia- nitrogen removal}

\subsubsection{Electrode surface reaction process}

Figure 7 illustrates the CV curves of high chlorine ammonia-nitrogen wastewater.. It can be seen that the curves were similar at different scanning speeds, with only one redox peak. When the voltage was approximately $1.05 \mathrm{~V}$, the current increased rapidly. This finding might be attributed to the generation of chlorine gas. The chloride ions diffused to the electrode surface were converted into chlorine gas, and the ammonia-nitrogen can be indirectly oxidized and removed by the chlorine gas in the electro-catalytic processes.

Figure 8 presents the Nyquist plot of the Pd-Sn-modified Ru-Ir electrode at concentrations of $5000 \mathrm{mg} / \mathrm{L}$ chloride ion and $80 \mathrm{mg} / \mathrm{L}$ ammonia-nitrogen ( $Z^{\prime}$ denotes the real part and $Z^{\prime \prime}$ denotes the imaginary part). Section $a \sim b$ was arc-shaped, presenting the stage of charge transfer control. After $b$, the curve changed differently with the increase of voltage. When the voltage was $1.1 \mathrm{~V}$, the mixture control of charge transfer and diffusion occurred between section b and c, and the straight line slope (near $45^{\circ}$ ) after Section $c$ indicated the stage of diffusion control. When the voltage increased to $1.2 \mathrm{~V}$, the slope between $\mathrm{b}$ and $\mathrm{d}$ was a straight line with a slope less than $45^{\circ}$, implying the stage of diffusion control in terms of barrier layer. After Section d, the curve presented an arc shape, suggesting the stage of charge transfer control. When the voltage was $1.15 \mathrm{~V}$, Section b presented a straight line with the slope less than $45^{\circ}$, suggesting the stage of diffusion control subject to barrier layer. Moreover, the voltage of $1.15 \mathrm{~V}$ seemed to be the critical conversion point between charge transfer control and diffusion control. In summary, there was a diffusion barrier layer between the electrode and the solution during the treatment of high chlorine ammonia-nitrogen wastewater. The barrier layer increased the contact resistance between chloride ions and the electrode surface, which was one of the limiting factors for the treatment of high chlorine ammonia-nitrogen wastewater. Therefore, it is necessary to control the electrode voltage to be greater than $1.15 \mathrm{~V}$ to break through the limitation of diffusion barrier layer, leading to the enhanced removal of ammonia-nitrogen.

\subsubsection{Properties of electrolytes}


Figure 9 shows the effect of electrolyte on ammonia-nitrogen removal at the initial ammonia-nitrogen concentration of $80 \mathrm{mg} / \mathrm{L}$. It can be seen that higher removal efficiency of ammonia-nitrogen was observed when sodium chloride was used as the electrolyte, compared to sodium sulfate. Furthermore, the ammonia-nitrogen removal rate of $100 \%$ was observed when the electro-catalytic reaction time was $40 \mathrm{~min}$ at chloride ion concentration of $5000 \mathrm{mg} / \mathrm{L}$. ,. By contrast, the removal rate of ammonia-nitrogen was only $13.19 \%$ at the concentration of sodium sulfate of $10000 \mathrm{mg} / \mathrm{L}, \backslash$ This finding indicated that the contribution of indirect electro-catalytic processes played an essential role in ammonia-nitrogen oxidation, accounting for $86.81 \%$ of the total ammonia-nitrogen removal. The chloride ions was first converted into chlorine gas by electrode, and then the ammonia-nitrogen was oxidized and removed by chlorine gas in the high chlorine ammonia-nitrogen wastewater. In the chlorine-free ammonia-nitrogen solution, ammonia-nitrogen was oxidized by directly contacting with the electrode or reacting with hydroxyl radicals on the electrode surface. In this process, a large number of oxygen evolution as side reactions occurred on the electrode surface, producing a large number of bubbles, which prevented the direct contact between ammonia-nitrogen and the electrode. Thus, the presence of hydroxyl radicals was short, resulting in extremely low ammonia-nitrogen removal without chlorine. In summary, indirect oxidation was the main process in the electro-catalytic oxidation for treating the high chlorine ammonianitrogen wastewater, and the chloride ion acted as the "oxidant" for the removal of ammonia-nitrogen.

\subsubsection{The oxidation products of ammonia-nitrogen}

Figure 10 illustrates the changes in the content of $\mathrm{NO}_{3}-\mathrm{N}, \mathrm{NO}_{2}-\mathrm{N}$ and $\mathrm{TN}$. The initial concentrations of ammonia-nitrogen, TN and chloride ion were $80 \mathrm{mg} / \mathrm{L}, 80 \mathrm{mg} / \mathrm{L}$, and $5000 \mathrm{mg} / \mathrm{L}$, respectively. Because only ammonia-nitrogen existed in the original high chlorine ammonia-nitrogen wastewater, $\mathrm{NO}_{3}-\mathrm{N}$ and $\mathrm{NO}_{2}-\mathrm{N}$ can be detected in the wastewater. At 50 min, the concentrations of nitrite and nitrite were $2.11 \mathrm{mg} / \mathrm{L}$ and $1.89 \mathrm{mg} / \mathrm{L}$, respectively, as the oxidation products of ammonia-nitrogen. At the same time, the removal rate of TN was increasing, and the removal rate of TN reached $95.01 \%$ at 50 min, indicating that nitrogen was nearly completely removed from the solution. Therefore, it can be inferred that nitrogencontaining substances in the wastewater were transformed into nitrogen and separated from the water. To sum up, the products of ammonia-nitrogen removal by electro-catalytic oxidation was nitrogen, in addition to a small amount of $\mathrm{NO}_{3}-\mathrm{N}$ and $\mathrm{NO}_{2}-\mathrm{N}$.

\subsubsection{Hydroxyl radical $(\cdot \mathrm{OH})$ analysis}

Figure 11 illustrates the schematic diagram of hydroxyl radical production at the initial ammonia-nitrogen and chloride ion concentrations of $80 \mathrm{mg} / \mathrm{L}$ and $5000 \mathrm{mg} / \mathrm{L}$. It was evidenced that hydroxyl radicals were generated in the process of ammonia-nitrogen removal. As shown in Fig. 11, the content of hydroxyl free radical increased significantly after $30 \mathrm{~min}$, however, the content was very low. The contribution of hydroxyl radicals to ammonia-nitrogen removal was trivial, due to the extremely low hydroxyl radicals content.

\subsubsection{Denitrification process}


The analysis of the intermediate products in the process of electro-catalytic oxidation for treating ammonia-nitrogen wastewater elucidates that under the action of the "oxidant" chloride ion, ammonianitrogen was eventually converted to nitrogen. Although the hydroxyl radical oxidation process may exist in the denitrification process, the contribution of free radical oxidation was minor. The specific denitrification process is shown in Fig. 12.

\section{Conclusions}

This study investigated the performance of modified Ru-Ir electrode with Pd-Sn for treating high chlorine ammonium-nitrogen wastewater. The effects of reaction conditions on the removal of ammonia-nitrogen, kinetics and possible denitrification process were also clarified. The main conclusions are as follows:

(1) The chlorine-evolution potential of Pd-Sn modified Ru-Ir electrode was $1.0956 \mathrm{~V}(v s$. SCE), which was much lower than that of commercial Ru-Ir electrode (1.1663 V).

(2) The Pd-Sn-modified Ru-Ir electrode can efficiently treat the high chlorine ammonia-nitrogen wastewater. With the initial ammonia-nitrogen and chloride ion concentrations of $80 \mathrm{mg} / \mathrm{L}$ and $5000 \mathrm{mg} / \mathrm{L}$, as well as current of $0.5 \mathrm{~A}$, the removal efficiency of ammonia-nitrogen could reach $100 \%$ at the reaction time of $40 \mathrm{~min}$.

(3) The rule of treating ammonia-nitrogen using electro-catalytic oxidation technology conformed to the zero-order kinetic equation, and the removal process was endothermic reaction with the apparent activation energy of $14.089 \mathrm{~kJ} / \mathrm{mol}$.

(4) Indirect oxidation played a vital role in the electro-catalytic denitrification of ammonia-nitrogen. With the "oxidant" chloride ion, ammonia-nitrogen was eventually converted to nitrogen. And the hydroxyl radicals made little contribution to oxidation denitrification in the electro-catalytic process.

\section{Declarations}

Ethics approval and consent to participate: not applicable.

Consent for publication: not applicable.

Availability of data and materials: not applicable.

Competing interests: The authors declare that they have no competing interests.

Funding: not applicable

Authors' contributions: Zhen-xing Yang proposed the idea of this research, wrote and discussed the results with all co-authors. Wen-yu Xie organized this article. Fang-fang Ye was responsible for measuring relevant experimental data, for instance the chlorine-evolution potential, removal rate of $\mathrm{NH}_{3}-\mathrm{N}$. De-hao $\mathrm{Li}$ 
got the equipment and chemical compounds to carry out experiments. All authors reviewed and approved the final manuscript.

Acknowledgements: not applicable

\section{References}

1. Mulder A, Graaf AA, Robertson LA, Kuenen JG (2006) Anaerobic ammonium oxidation discovered in a denitrifying fluidized bed reactor. Fems Microbiology Ecology 16(2006):177-184

2. Daekeun Kim T-S, Kim H-D, Ryu S-I, Lee (2008) Treatment of low carbon-to-nitrogen wastewater using two-stage sequencing batch reactor with independent nitrification. Process Biochem 43(2008):406413. https://doi.org/10.1016/j.procbio.2008.01.003

3. Dayanne CC, De A, Cynthia Kérzia Costa de Araújo A, Ca Rmem LP, B, Ricardo Salazar C, Ca Rlos Alberto Martínez-Huitle A (2014) Active chlorine species electrogenerated on Ti/ $\mathrm{Ru}_{0.3} \mathrm{Ti}_{0.7} \mathrm{O}_{2}$ surface: Electrochemical behavior, concentration determination and their application. Journal of Electroanalytical Chemistry 731(2014):145-152

4. Zhang E, Wang B, Wang Q, Zhang S, Zhao B (2008) Ammonia-nitrogen and orthophosphate removal by immobilized Scenedesmus sp. isolated from municipal wastewater for potential use in tertiary treatment. Biores Technol 99(2008):3787-3793. https://doi.org/10.1016/j.biortech.2007.07.011

5. Diwani GE, Rafie ShE, El Ibiari NN, El-Aila HI (2007) Recovery of ammonia nitrogen from industrial wastewater treatment as struvite slow releasing fertilizer. Desalination 214(2007):200-214. https://doi.org/10.1016/j.desal.2006.08.019

6. Ruiz G, Jeison D, Chamy R (2003) Nitrification with high nitrite accumulation for the treatment of wastewater with high ammonia concentration. Water Res 37(2003):1371-1377. https://doi.org/10.1016/S0043-1354(02)00475-X

7. Kurama H, Poetzschke J, Haseneder R (2002) The application of membrane filtration for the removal of ammonium ions from potable water. Water Research 36(2002):2905-2909. https://doi.org/10.1016/S0043-1354(01)00531-0

8. Haiming Huang J, Liu P, Zhang D, Zhang F, Gao (2017) Investigation on the simultaneous removal of fluoride, ammonia nitrogen and phosphate from semiconductor wastewater using chemical precipitation. Chem Eng J 307(2017):696-706. https://doi.org/10.1016/j.cej.2016.08.134

9. Haiming Huang J, Yang D, Li (2014) Recovery and removal of ammonia-nitrogen and phosphate from swine wastewater by internal recycling of struvite chlorination product. Biores Technol 172(2014):253-259. https://doi.org/10.1016/j.biortech.2014.09.024

10. Hanxin Huo H, Lin Y, Dong H, Cheng H, Wang L Cao (2012) Ammonia-nitrogen and phosphates sorption from simulated reclaimed waters by modified clinoptilolite. J Hazard Mater 229230(2012):292-297. https://doi.org/10.1016/j.jhazmat.2012.06.001

11. Hao Wang Y, Yang X, Liu H, Zhong G, Bo Y, Zhang (2016) Decomposition of Ammonia Nitrogen from Biologically Pretreated Coking Wastewater with Electrochemical Three-dimensional Ti/RuO $/ \mathrm{IrO}_{2}$ 
Electrodes. Nature Environment and Pollution Technology 15(2016):881

12. Fang H-Y, Chou M-S, Huang C-W (1993) Nitrification of ammonia-nitrogen in refinery wastewater. Water Research 27(1993):1761-1765. https://doi.org/10.1016/0043-1354(93)90114-W

13. Ingo Schmidt E, Bock (1997) Anaerobic ammonia oxidation with nitrogen dioxide by Nitrosomonas eutropha. Archives of Microbiology 167(1997):106-111

14. Izzet Ozturk M, Altinbas I, Koyuncu O, Arikan, Cigdem Gomec-Yangin (2003) Advanced physicochemical treatment experiences on young municipal landfill leachates. Waste Management 23(2003):441-446. https://doi.org/10.1016/S0956-053X(03)00061-8

15. Ding J, Wei L, Huang H, Zhao Q, Hou W, Kabutey FT, Yuan Y, Dionysiou DD (2018) Tertiary treatment of landfill leachate by an integrated Electro-Oxidation/Electro-Coagulation/Electro-Reduction process: Performance and mechanism. J Hazard Mater 351(2018):90-97.

10.1016/j.jhazmat.2018.02.038

16. Liu J, Zhong C, Yang Y, Wu YT, Jiang AK, Deng YD, Zhang Z, Hu WB (2012) Electrochemical preparation and characterization of Pt particles on ITO substrate: Morphological effect on ammonia oxidation. International Journal of Hydrogen Energy 37(2012):8981-8987

17. Li J, Wei J, Ngo HH, Guo W, Liu H, Du B, Wei Q, Wei D (2018) Characterization of soluble microbial products in a partial nitrification sequencing batch biofilm reactor treating high ammonia nitrogen wastewater. Biores Technol 249(2018):241-246. https://doi.org/10.1016/j.biortech.2017.10.013

18. Chen J, Shi H, Lu J (2007) Electrochemical treatment of ammonia in wastewater by $\mathrm{RuO}_{2}-\mathrm{IrO}_{2}-$ $\mathrm{TiO}_{2} / \mathrm{Ti}$ electrodes. Journal of Applied Electrochemistry 37(2007):1137-1144

19. Kuo Fang H, Gong W, He F, Peng C, He K, Wang (2018) Recovering ammonia from municipal wastewater by flow-electrode capacitive deionization. Chemical Engineering Journal 348(2018):301309

20. Kim K-W, Kim Y-J, Kim I-T, Park Gun-II, Lee E-H (2006) Electrochemical conversion characteristics of ammonia to nitrogen. Water Res 40(2006):1431-1441.

https://doi.org/10.1016/j.watres.2006.01.042

21. Laisa Candido JACP, Gomes, Hermano Cezar Medaber Jambo (2013) Electrochemical treatment of oil refinery wastewater for $\mathrm{NH}_{3}-\mathrm{N}$ and COD removal. Int. J. Electrochem. Sci 8(2013):9187-9200

22. Li Lin J, Chen Z, Xu S, Yuan M, Cao H, Liu X, Lu (2009) Removal of ammonia nitrogen in wastewater by microwave radiation: A pilot-scale study. J Hazard Mater 168(2009):862-867. https://doi.org/10.1016/j.jhazmat.2009.02.113

23. Li Lin S, Yuan J, Chen Z, Xu X, Lu (2009) Removal of ammonia nitrogen in wastewater by microwave radiation. Journal of Hazardous Materials 161(2009):1063-1068.

https://doi.org/10.1016/j.jhazmat.2008.04.053

24. Li Z, Claude E, Boyd (2014) Total ammonia nitrogen removal from aqueous solutions by the natural zeolite, mordenite: A laboratory test and experimental study. Aquaculture 432(2014):252-257. https://doi.org/10.1016/j.aquaculture.2014.05.019 
25. Chen $L$, Zhang $Y$, Chengbo Ma (2020) Perovskites $\mathrm{Sr}_{x} \mathrm{La}_{1-x} \mathrm{Mn}_{y} \mathrm{Co}_{1-y} \mathrm{O}_{3-\delta}$ coated on Ti as stable nonnoble anode for efficient electrocatalytic oxidation of organic wastewater containing ammonia nitrogen. Chemical Engineering Journal 393(2020):10.1016/j.cej.2020.124514

26. Strous M, Gerven EV, Zheng P, Gijs Kuenen J, Jetten MSM (1997) Ammonium removal from concentrated waste streams with the anaerobic ammonium oxidation (Anammox) process in different reactor configurations. Water Research 31(1997):0-1962

27. Li M, Feng C, Zhang Z, Yang S, Sugiura N (2010) Treatment of nitrate contaminated water using an electrochemical method. Bioresource Technology 101(2010):6553-6557. https://doi.org/10.1016/j.biortech.2010.03.076

28. Shaban M, Abukhadra MR, Nasief FM, Abd El-Salam HM (2017) Removal of Ammonia from Aqueous Solutions, Ground Water, and Wastewater Using Mechanically Activated Clinoptilolite and Synthetic Zeolite-A: Kinetic and Equilibrium Studies. Water Air \& Soil Pollution 228(2017):450

29. Duong P-H, Pham C-M, Ngoc-Han T, Huynh Y-S Yoon (2018) Removal of Ammonia Nitrogen in Wastewater by Indirect Mechanism Using Electrochemical Method with Platinum Electrode as Anode. Nature Environment and Pollution Technology 17(2018):1331-1338

30. RM Abdel Hameed (2017) Facile preparation of Pd-metal oxide/C electrocatalysts and their application in the electrocatalytic oxidation of ethanol. Applied Surface Science 411(2017):91-104

31. Salvador Alcocer A, Picos AR, Uribe, Tzayam Pérez, Juan M, Peralta-Hernández (2018) Comparative study for degradation of industrial dyes by electrochemical advanced oxidation processes with BDD anode in a laboratory stirred tank reactor. Chemosphere 205(2018):682-689. https://doi.org/10.1016/j.chemosphere.2018.04.155

32. Jing S-R, Ying-Feng Lin (2004) Seasonal effect on ammonia nitrogen removal by constructed wetlands treating polluted river water in southern Taiwan. Environmental Pollution 127(2004):291301. https://doi.org/10.1016/S0269-7491(03)00267-7

33. Wang S, Wu X, Wang Y, Li Q, Tao M (2008) Removal of organic matter and ammonia nitrogen from landfill leachate by ultrasound. Ultrason Sonochem 15(2008):933-937

34. Wei Xu R, Lan D, Du J, Humphreys M, Walker Z, Wu H, Wang S, Tao (2017) Directly growing hierarchical nickel-copper hydroxide nanowires on carbon fibre cloth for efficient electrooxidation of ammonia. Applied Catalysis B: Environmental 218(2017):470-479

35. Xiao-bo MIN, Min ZHOU, Li-yuan CHAl, Yun-yan WANG, Yu-de SHU (2009) Treatment of nickelammonia complex ion-containing ammonia nitrogen wastewater. Transactions of Nonferrous Metals Society of China 19(2009):1360-1364. https://doi.org/10.1016/S1003-6326(08)60450-1

36. Zhang X, Zhu F, Chen L, Zhao Q, Tao G (2013) Removal of ammonia nitrogen from wastewater using an aerobic cathode microbial fuel cell. Bioresource Technology 146(2013):161-168. https://doi.org/10.1016/j.biortech.2013.07.024

37. Xuli Ma R, Wang W, Guo H, Yang Z, Liang C Fan (2012) Electrochemical removal of ammonia in coking wastewater using $\mathrm{Ti} / \mathrm{SnO}_{2}+\mathrm{Sb} / \mathrm{PbO}_{2}$ anode. Int. J. Electrochem. Sci 7(2012):6012 
38. He X, Chai Z, Li F, Zhang C, Li D, Li J, Jianlong Hu (2013) Advanced treatment of biologically pretreated coking wastewater by electrochemical oxidation using $\mathrm{Ti} / \mathrm{RuO}_{2}-\mathrm{IrO}_{2}$ electrodes. Journal of chemical technology and biotechnology (1986) 88(2013):1568-1575. 10.1002/jctb.4006

39. Shavisi Y, Sharifnia S, Hosseini SN, Khadivi MA (2014) Application of $\mathrm{TiO}_{2} /$ perlite photocatalysis for degradation of ammonia in wastewater. Journal of Industrial and Engineering Chemistry 20(2014):278-283

40. Liu Y, Li L, Ramesh Goel (2009) Kinetic study of electrolytic ammonia removal using $\mathrm{Ti} / \mathrm{IrO}_{2}$ as anode under different experimental conditions. Journal of Hazardous Materials 167(2009):959-965. https://doi.org/10.1016/j.jhazmat.2009.01.082

41. Zhang Y, Li J, Bai J, Li X, Shen Z, Xia L, Chen S, Xu Q, Zhou B (2018) Total organic carbon and total nitrogen removal and simultaneous electricity generation for nitrogen-containing wastewater based on the catalytic reactions of hydroxyl and chlorine radicals. Applied Catalysis B: Environmental 238(2018):168-176. https://doi.org/10.1016/j.apcatb.2018.07.036

42. Yang Zhou B, Xiao S-Q, Liu Z, Meng Z-G, Chen C-Y, Zou C-B, Liu F, Chen X Zhou (2016) Photo-Fenton degradation of ammonia via a manganese-iron double-active component catalyst of graphenemanganese ferrite under visible light. Chemical Engineering Journal 283(2016):266-275

43. Ruan Y, Lu C, Guo X, Deng Y, Zhu S (2016) Electrochemical treatment of recirculating aquaculture wastewater using a $\mathrm{Ti} / \mathrm{RuO}_{2}-\mathrm{IrO}_{2}$ anode for synergetic total ammonia nitrogen and nitrite removal and disinfection. Transactions of the Asabe 59(2016):1831-1840

44. Ye Z, Zhang H, Yang L, Wu L, Qian Y, Geng J, Chen M (2016) Effect of a solar Fered-Fenton system using a recirculation reactor on biologically treated landfill leachate. J Hazard Mater 319(2016):5160. 10.1016/j.jhazmat.2016.01.027

45. Zhou Yin-fang (2010) SBR Treating High-salinity Oil Exploration Produced Wastewater. Master Degree, Chang'an University

\section{Figures}




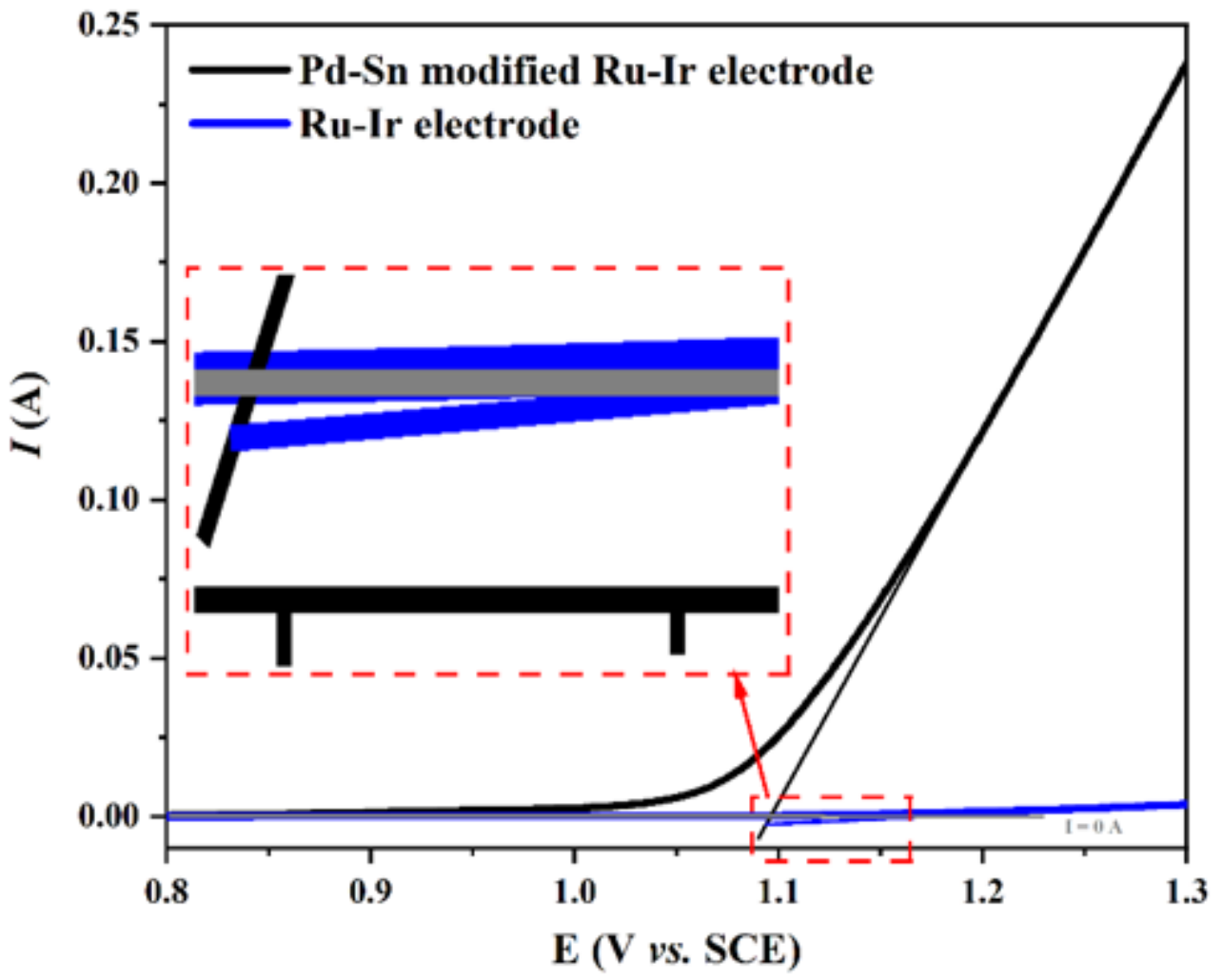

Figure 1

Linear scan voltammogram curves of Pd-Sn modified Ru-Ir electrodes in saturated sodium chloride(SCE) at scan rate of $5 \mathrm{mV} / \mathrm{s}$. 


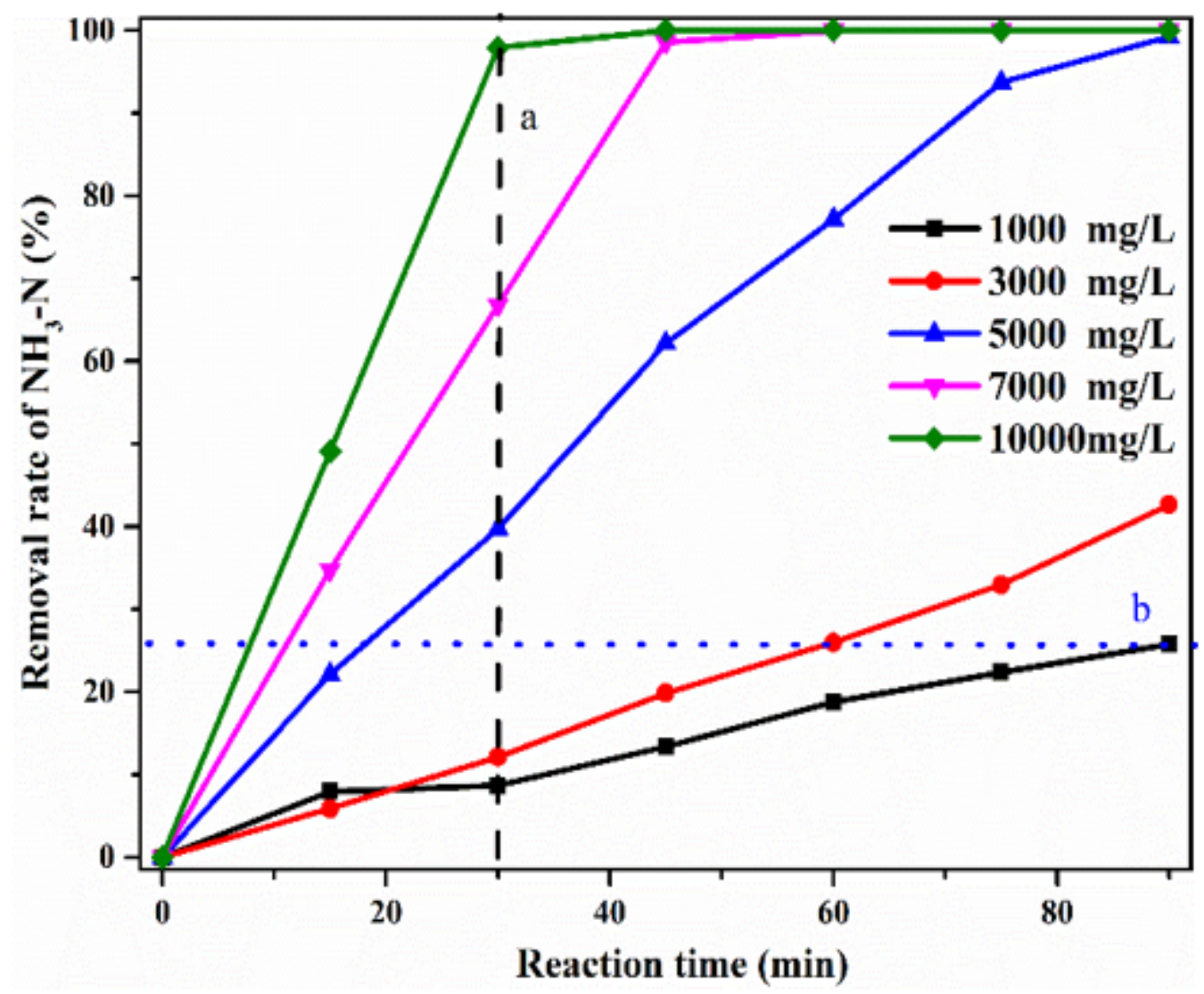

Figure 2

Influence of chloride ion concentration on removal of ammonia-nitrogen 


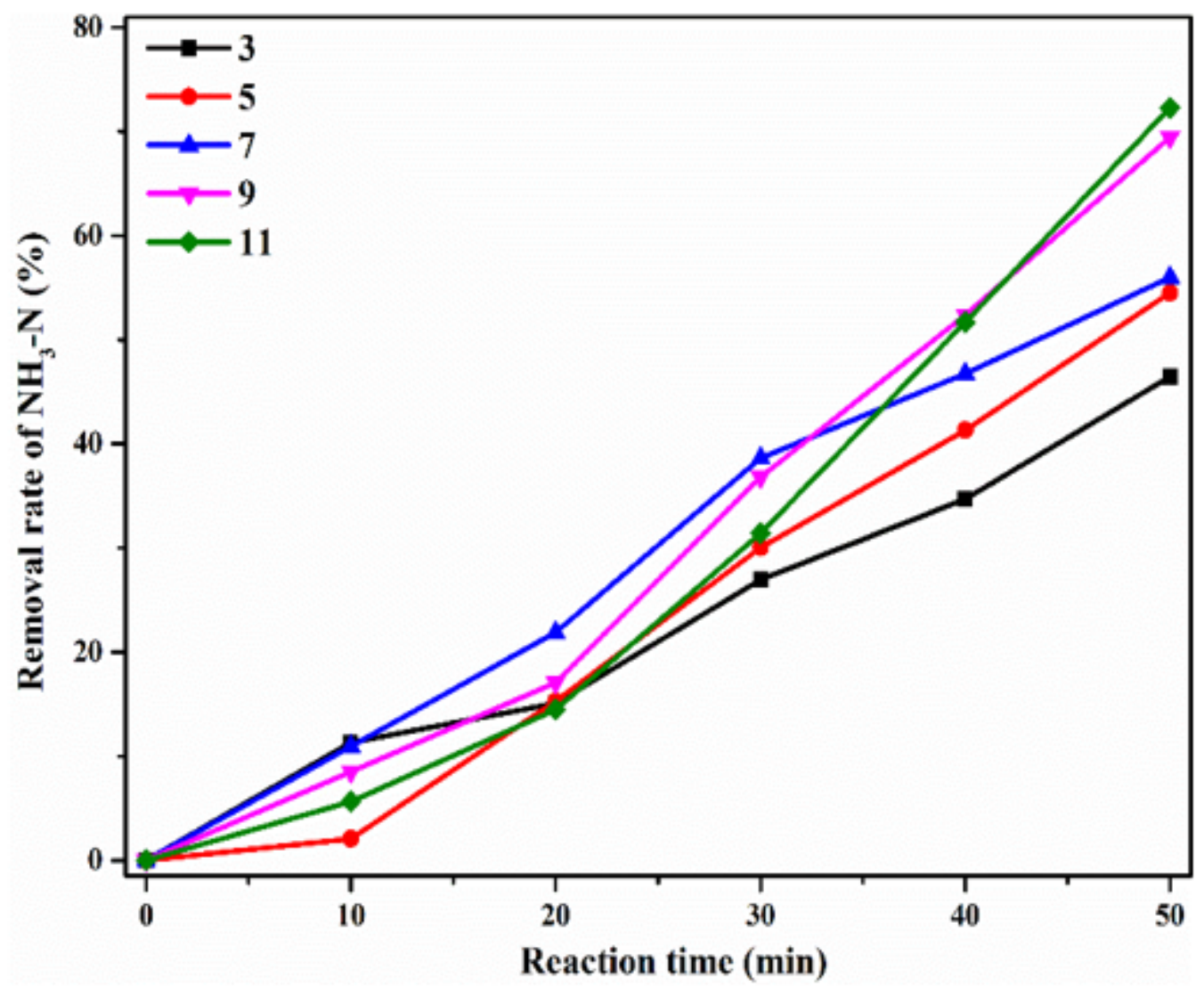

Figure 3

Effect of $\mathrm{pH}$ value on removal of ammonia-nitrogen 


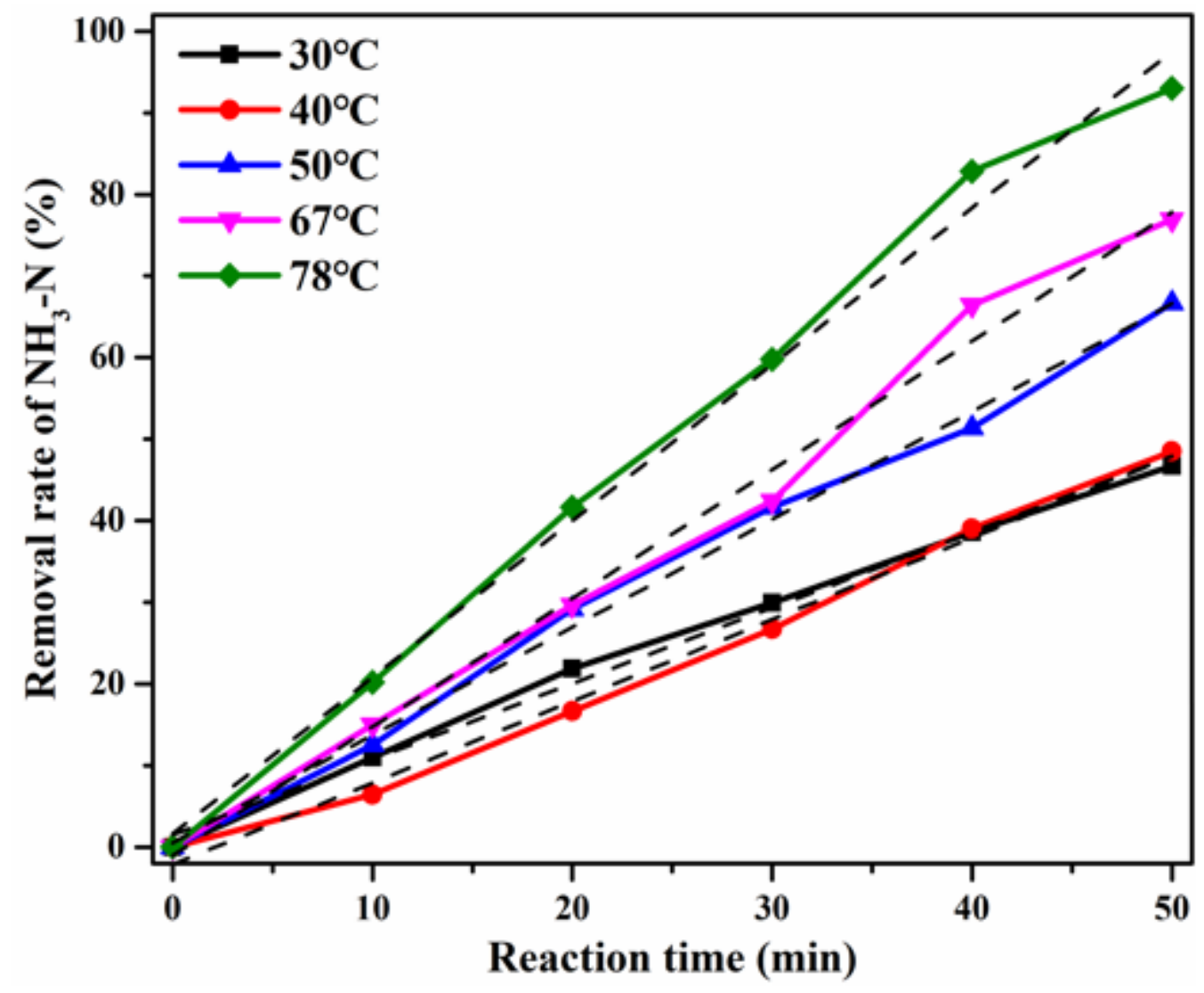

Figure 4

Effect of reaction temperature on ammonia-nitrogen removal 

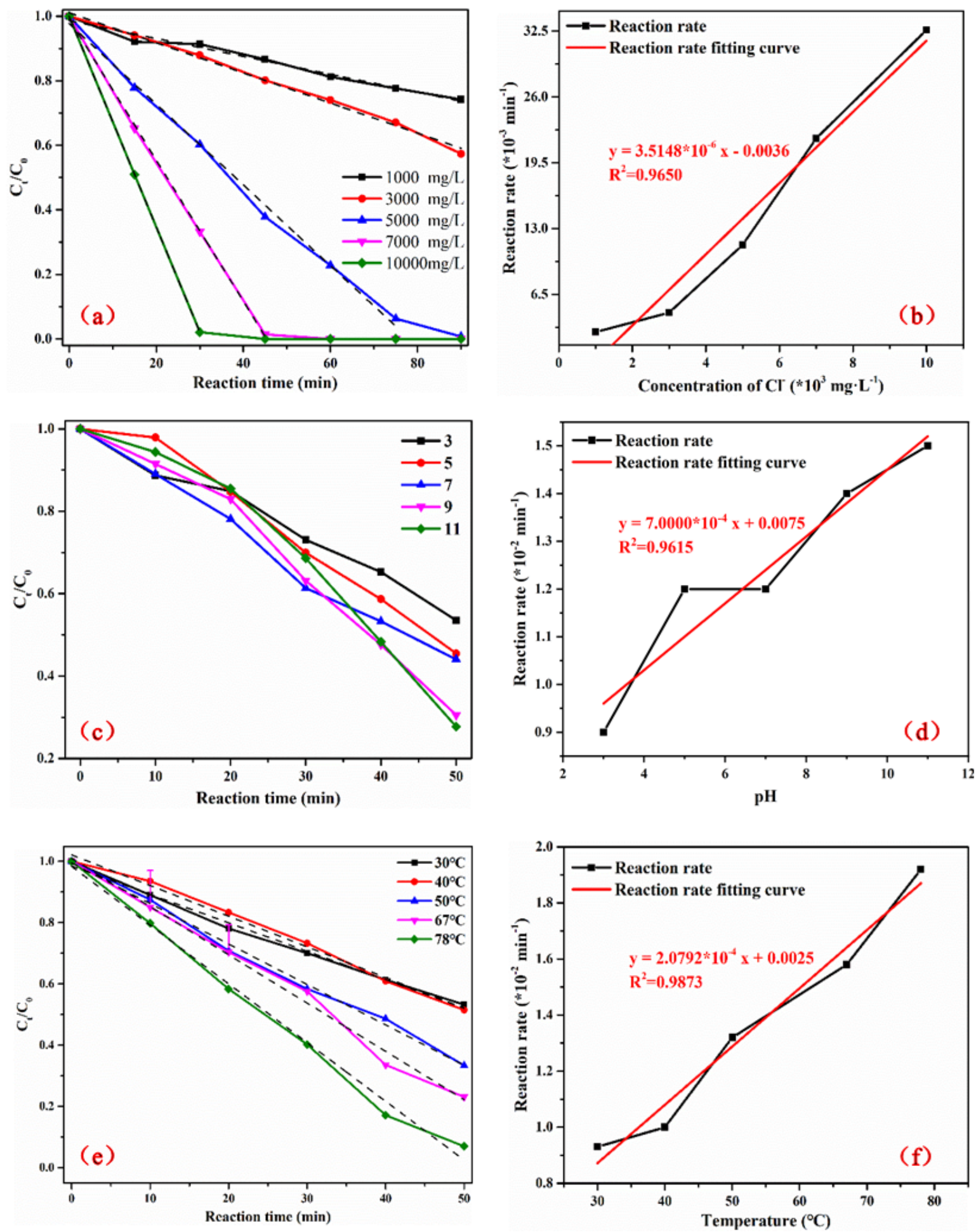

\section{Figure 5}

Influence of reaction conditions on ammonia-nitrogen removal kinetics. (a), (c) and (e) are the influence of chloride concentration, $\mathrm{pH}$ value and temperature on the removal effect of ammonia-nitrogen, respectively (The dashed line is the linear regression fitting line). (b), (d) and (f) are the relationship curves of chloride concentration, $\mathrm{pH}$ value and temperature on the reaction rate $(\mathrm{k})$, respectively. 


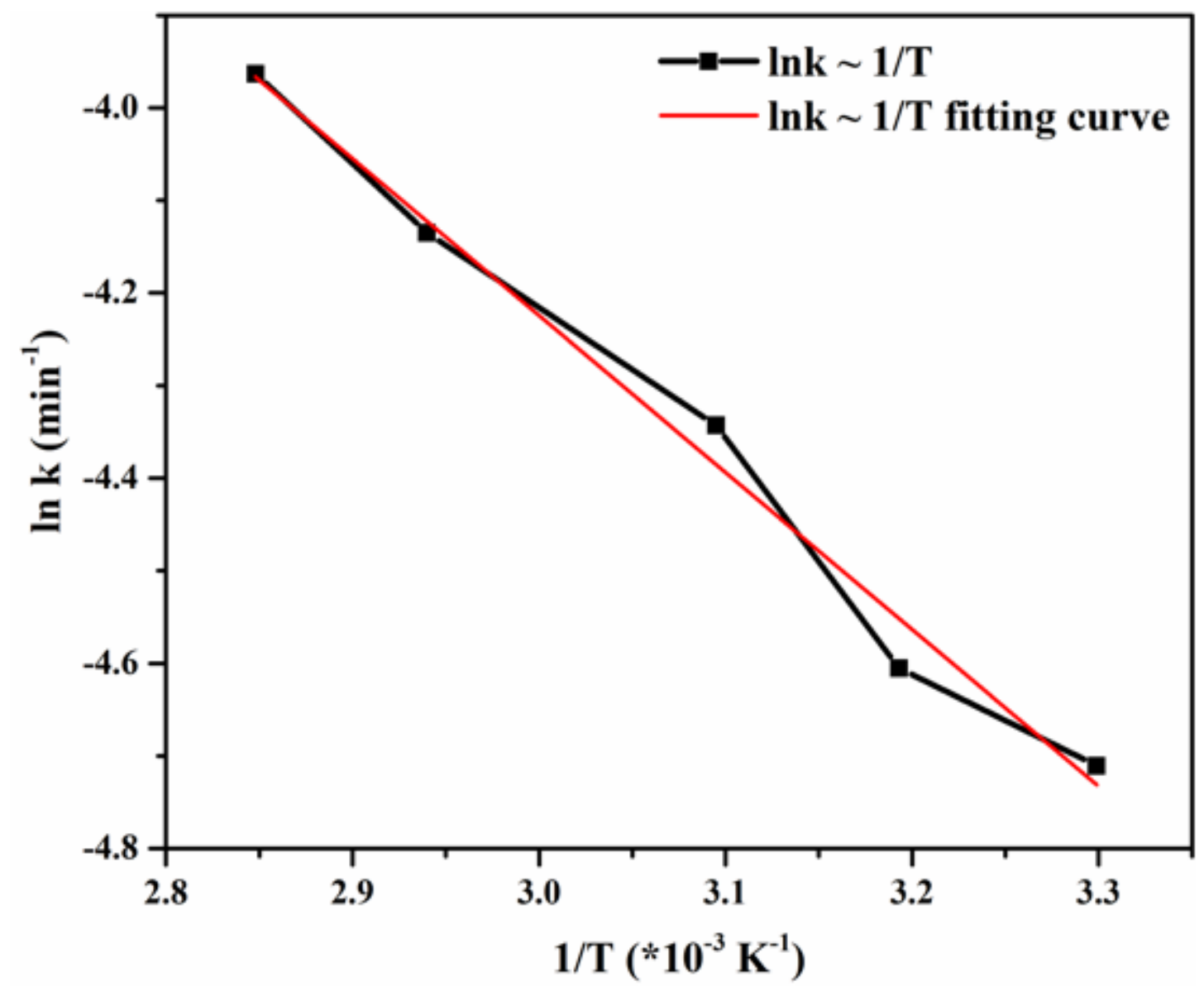

Figure 6

Ink 1/T diagram 


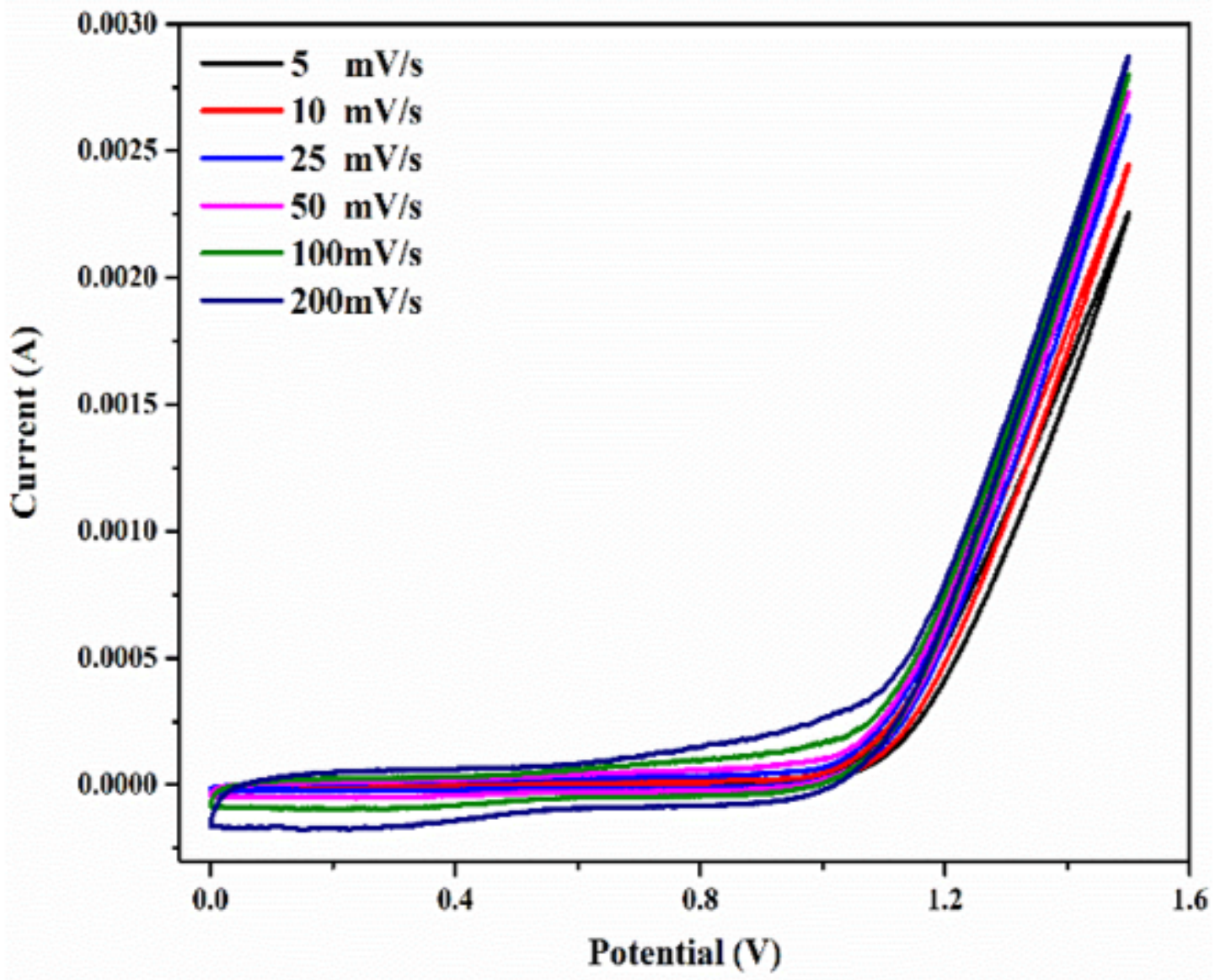

Figure 7

The CV curves of high chlorine ammonia-nitrogen wastewater 


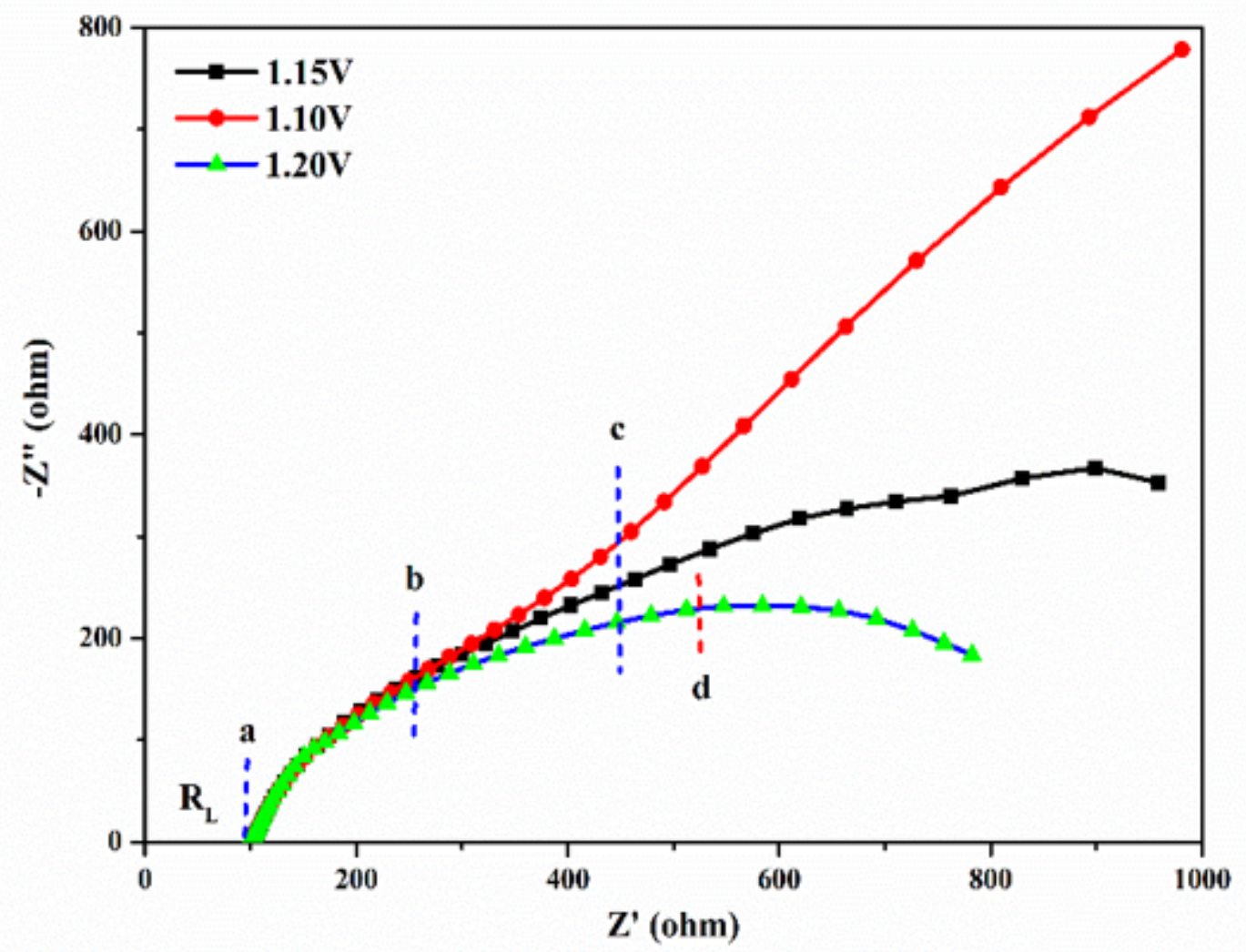

Figure 8

Nyquist plot of wastewater with high chlorinated ammonia-nitrogen 


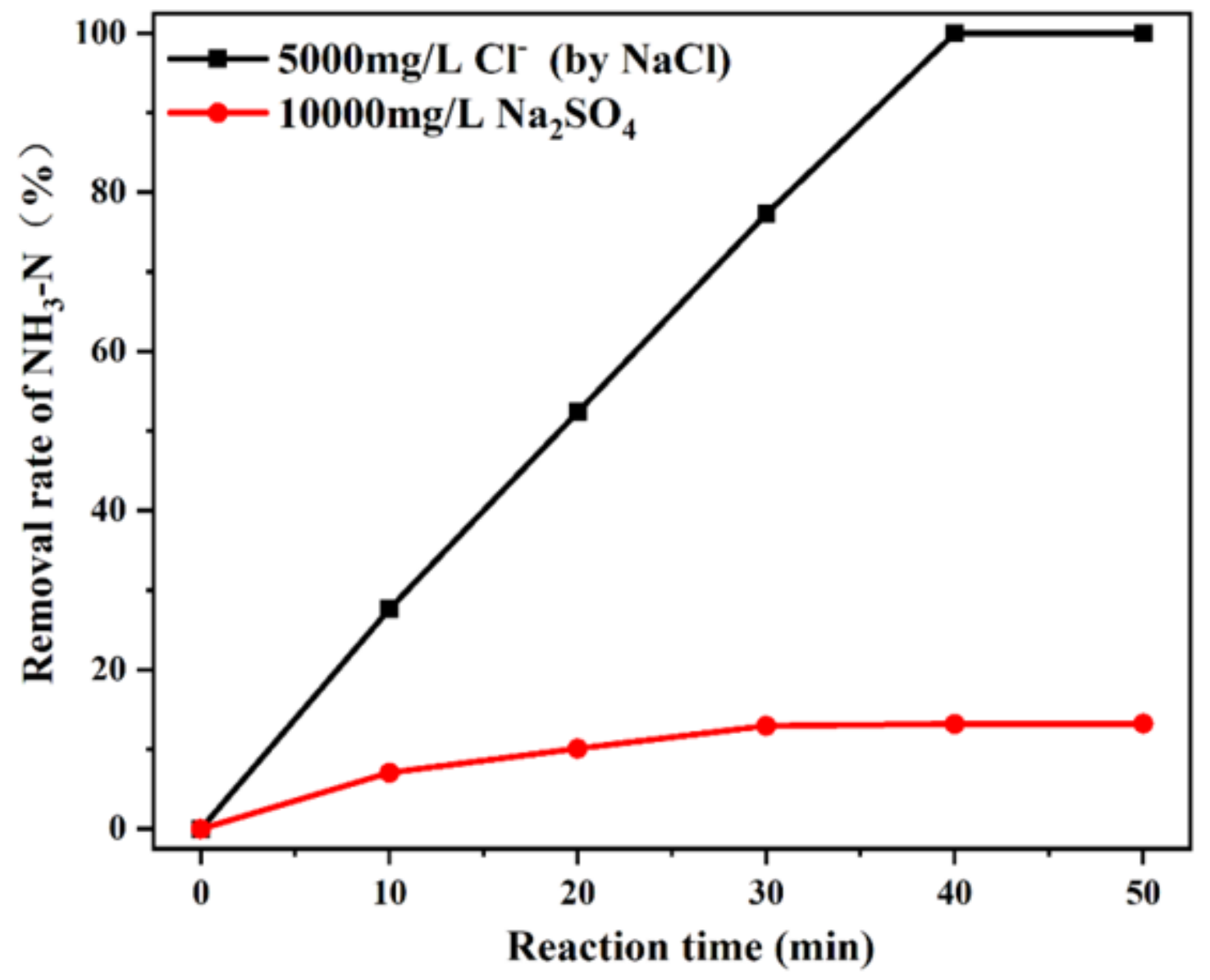

Figure 9

Influence of electrolyte on the removal of ammonia nitrogen 


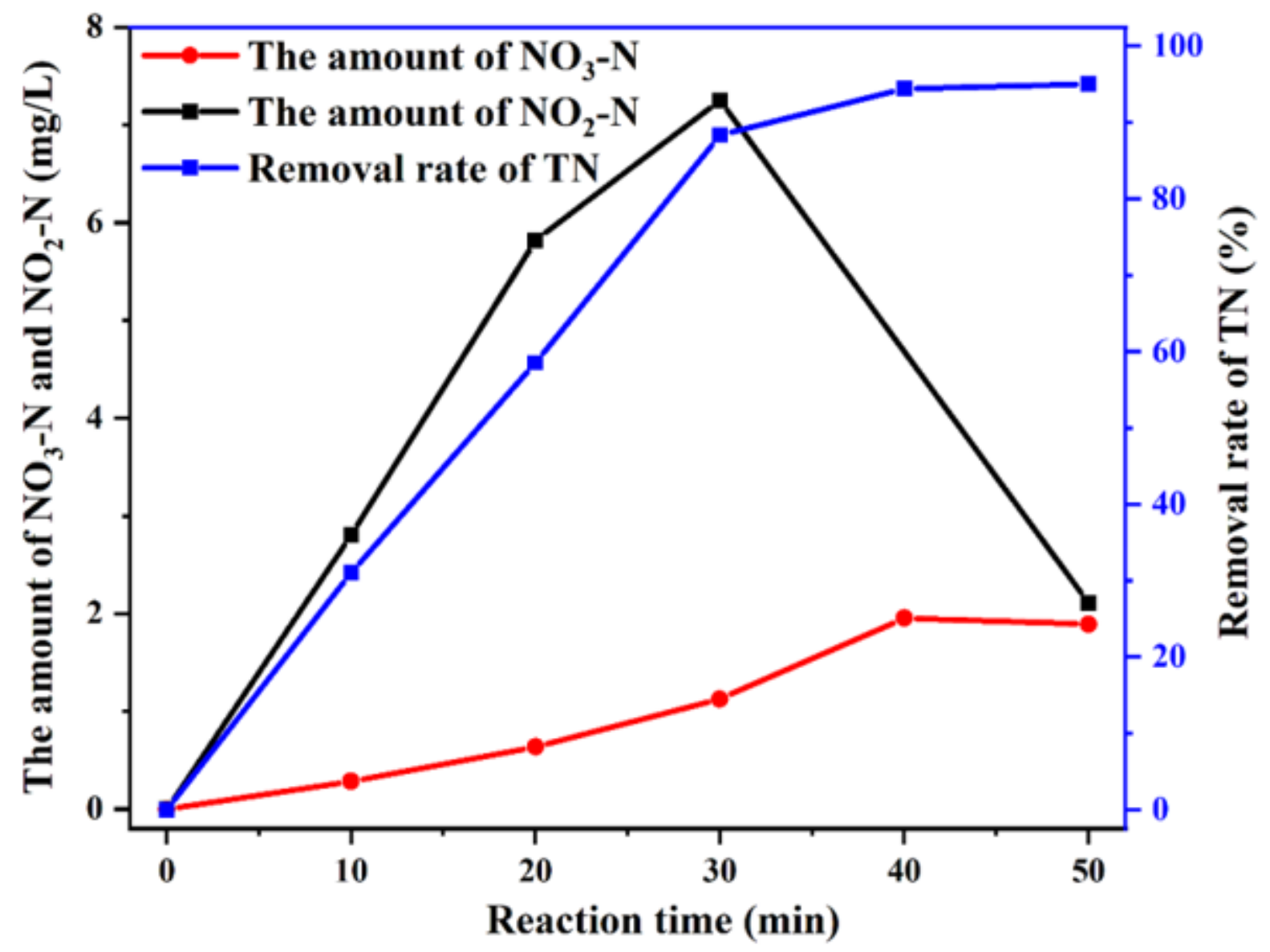

Figure 10

The amount of NO3-N, NO2-N and TN 


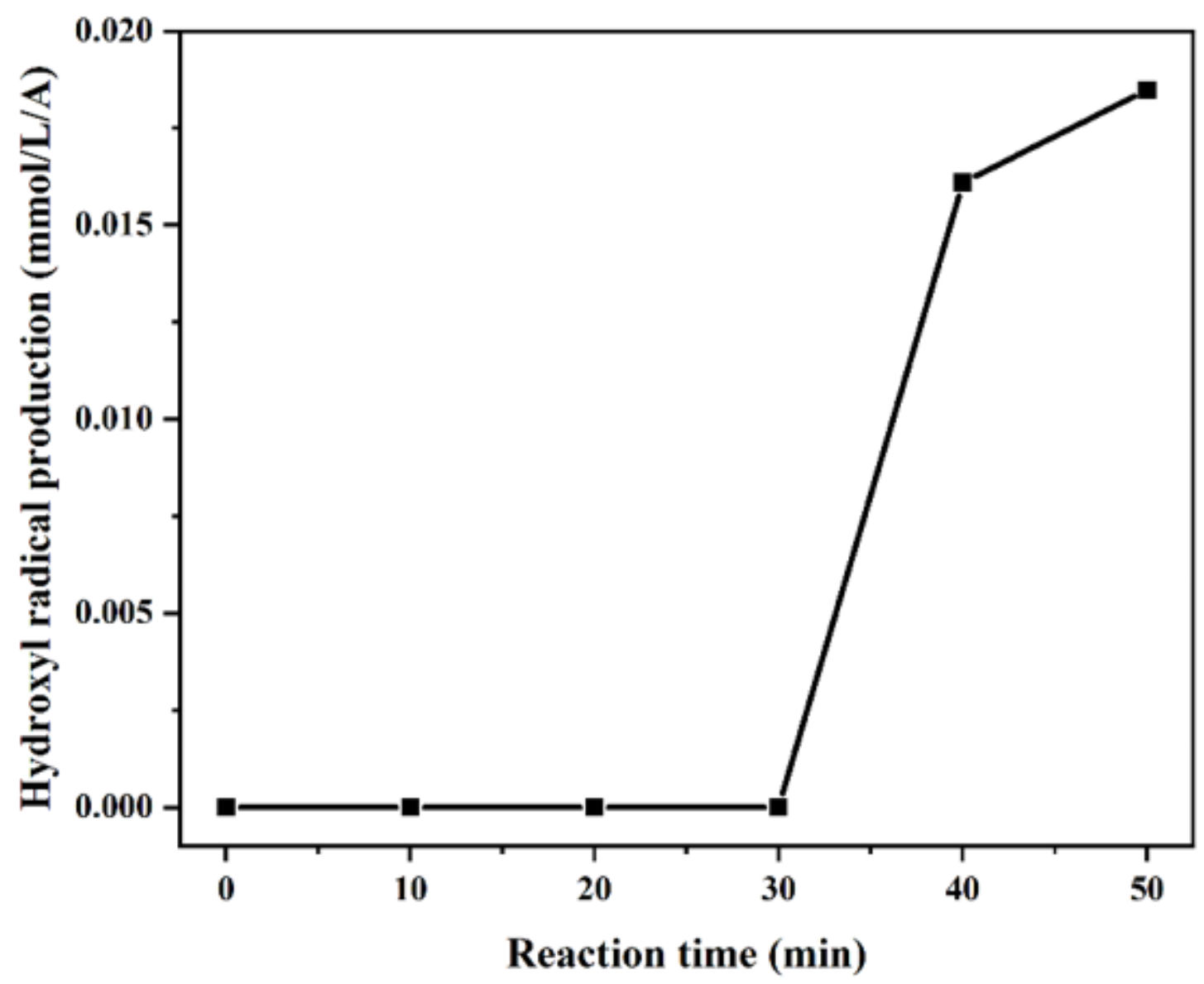

Figure 11

Hydroxyl radical production

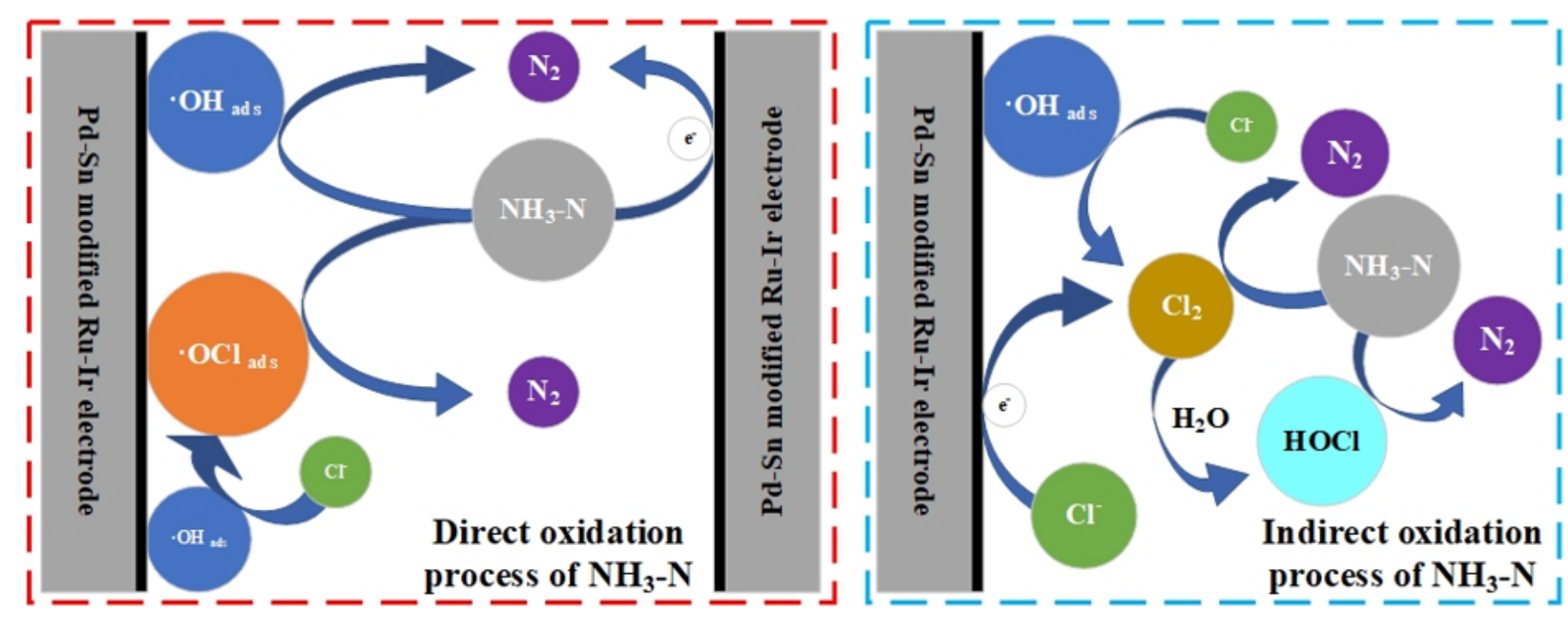

Figure 12

Denitrification process of electro-catalytic oxidation of ammonia-nitrogen 